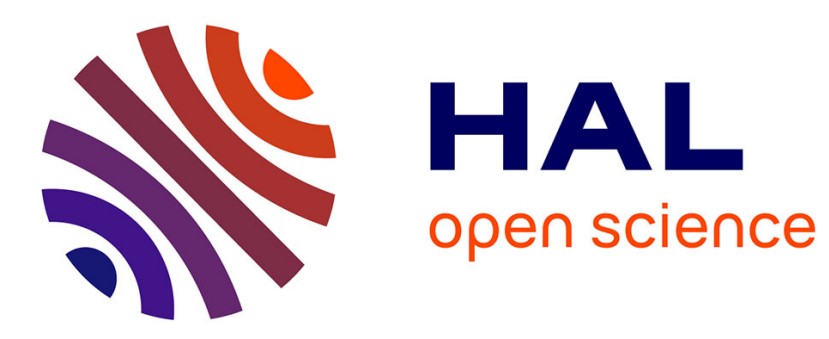

\title{
The Term Structure of Interest Rates in the New and Prospective EU Countries
}

\author{
Minoas Koukouritakis, Leo Michelis
}

\section{To cite this version:}

Minoas Koukouritakis, Leo Michelis. The Term Structure of Interest Rates in the New and Prospective EU Countries. Applied Economics, 2008, 40 (04), pp.479-490. 10.1080/00036840600690249 . hal00581964

\section{HAL Id: hal-00581964 https://hal.science/hal-00581964}

Submitted on 1 Apr 2011

HAL is a multi-disciplinary open access archive for the deposit and dissemination of scientific research documents, whether they are published or not. The documents may come from teaching and research institutions in France or abroad, or from public or private research centers.
L'archive ouverte pluridisciplinaire HAL, est destinée au dépôt et à la diffusion de documents scientifiques de niveau recherche, publiés ou non, émanant des établissements d'enseignement et de recherche français ou étrangers, des laboratoires publics ou privés. 


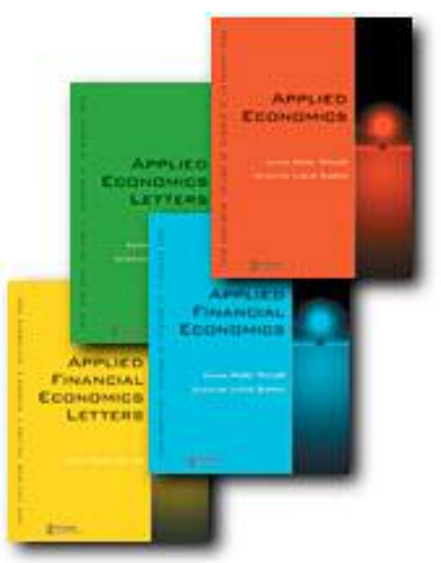

The Term Structure of Interest Rates in the New and Prospective EU Countries

\begin{tabular}{|c|c|}
\hline Journal: & Applied Economics \\
\hline Manuscript ID: & APE-05-0380.R1 \\
\hline Journal Selection: & Applied Economics \\
\hline $\begin{array}{r}\text { Date Submitted by the } \\
\text { Author: }\end{array}$ & 18-Nov-2005 \\
\hline JEL Code: & $\begin{array}{l}\text { E43 - Determination of Interest Rates|Term Structure of Interest } \\
\text { Rates < , F42 - International Policy Coordination and Transmission } \\
<, \text { F15 - Economic Integration }<\end{array}$ \\
\hline Keywords: & $\begin{array}{l}\text { Term Structure, Granger Causality, Common Trends, Cointegration, } \\
\text { EU Enlargement }\end{array}$ \\
\hline
\end{tabular}

powered by ScholarOne

Manuscript Central ${ }^{\mathrm{M}}$ 


\title{
The Term Structure of Interest Rates
}

\section{in the New and Prospective EU Countries}

\author{
Minoas Koukouritakis* \\ Department of Economics \\ University of Crete \\ University Campus \\ Rethymno 74100 \\ Greece
}

\author{
Leo Michelis ${ }^{\dagger}$
}

Department of Economics

Ryerson University

350 Victoria Street

Toronto, Ontario

Canada, M5B 2K3

\section{The Term Structure in the New and Prospective EU Countries}

\begin{abstract}
This paper uses cointegration and common trends techniques to investigate empirically the expectations hypothesis of the term structure of interest rates for the 10 new EU countries, along with Bulgaria and Romania. The empirical results support the expectations theory of the term structure for all countries except Malta. By decomposing each term structure into its transitory and permanent components, we also analyze short run and long run interdependence among the term structures of interest rates in these countries. Our results indicate only weak linkages among the term structures of the 10 new EU countries, and strong linkages between Bulgaria and Romania that hope to join the EU in 2007.
\end{abstract}

JEL Classification: E43, F15, F42

Keywords: Term Structure, EU Enlargement, Cointegration, Common Trends, Granger Causality.

${ }^{*}$ Corresponding author: Department of Economics, University of Crete, University Campus, Rethymno 74100, Greece. Tel.: +30 2831077435, fax: +30 2831077406, e-mail: minoas@econ.soc.uoc.gr

${ }^{\dagger}$ We would like to thank the editor of the journal for useful suggestions that have improved the exposition of the paper. The second author would like to thank the Social Sciences and Humanities Research Council of Canada for financial support. All the remaining errors are our own. 


\section{Introduction}

The enlargement process of an economic union is an important issue in the theory and practice of economic integration. In the framework of the European Union (EU), enlargement has been a concern since the foundation of the European Economic Community by the Treaty of Rome in 1957. The Treaty states explicitly that one of its main objectives is the continuous and balanced expansion. Indeed the current EU is the result of various expansions since 1957 .

After growing in size from the original six members to twelve members and then to fifteen member states, the EU has recently experienced its biggest expansion ever in terms of scope and diversity. On May 1, 2004 ten countries joined the Union. These countries are Cyprus, the Czech Republic, Estonia, Hungary, Latvia, Lithuania, Malta, Poland, the Slovak Republic and Slovenia. In order to successfully join the EU these countries had to satisfy certain economic and political criteria, which include being stable democracies, respect human rights and the rule of law as well as having a functioning market economy. Currently, two more countries, Bulgaria and Romania, hope to join the EU in 2007.

The Maastricht Treaty has laid down explicit nominal convergence criteria that must be satisfied before a candidate country can join the European Monetary Union (EMU) successfully. One criterion concerns the convergence of long term interest rates to the average interest rate of the three EMU countries with the lowest inflation rates. In the present paper we investigate interest rate linkages among the new and prospective EU countries using the expectations hypothesis of the term structure (EHTS) of interest rates. According to the EHTS, the interest rate on a long run government security is an average of the current short rate and the expected future rates on securities of shorter maturity. If future short rates are expected to be constant over time, then the yields curve will be a horizontal line at the level of the current short rate. If future short rates are expected to rise, then the yield curve will be upward slopping, while if future short rates are expected to fall, then the yield curve will be downward slopping. Thus, the EHTS provides a plausible link between short and long term interest rates over time.

Clearly the EHTS has important policy implications. The term structure is a channel through which government policies can affect the long term prospects of an economy. For example, if a government adopts policies that lower the expected future short rates, then the long term interest rate will be lower and consequently, investment and economic growth will be higher.

The literature on the term structure of interest rates is large and growing; see Shiller (1990) for an excellent survey of theory and empirical studies. The recent empirical literature has employed various econometric techniques such as cointegration, vector autoregressions and Kalman filtering and is, in general, supportive of the EHTS of 
interest rates. Among others, Hall, Anderson and Granger (1992) used monthly data from 1970:3 to 1988:12 for 12 yield series of US Treasury Bills and found evidence supportive of the EHTS. Hardouvelis (1994) used monthly data of different time spans for the G7 countries: Canada, France, Germany, Italy, Japan, the UK and the USA. He found that the expectations hypothesis holds for all countries except the USA. Gerlach and Smets (1997) studied the term srtuctures in a sample 17 countries with time spans between 10 and 30 years, and monthly data for 1-month, 3-month, 6-month and 12-month euro rates. Using cross-sectional regression analysis, they concluded that for most of the countries the EHTS is compatible with the data. Wolters (1998) tested the EHTS for seven German interest rates, with monthly data from 1977:1 to 1993:12. He concluded that the strong form of the EHTS does not hold for the German bond market. McDermott (1998) studied three English interest rates of the eighteenth century, using quarterly data from 1719:4 to 1797:3, while Balcombe and Tiffin (2002) tested the EHTS for four UK interest rates with monthly data from 1975:1 to 2001:1. Each of these two studies found evidence in support of the EHTS. Dominguez and Novales (2002) analyzed interest rates on euro-deposits from the London euro-currency market, using monthly data over the period 1979:1 to 1998:12, and found evidence consistent with the EHTS. Anatolyev and Korepanov (2003) examined the Moscow interbank offered rates for a sample of daily observations from January 1, 2000 to May 1, 2003. They concluded that the yield curve is increasing and slightly concave, a result that is in favor of the EHTS. Chen (2001), Cassola and Luis (2003) and Gravelle and Morley (2005) adopted the Kalman filter technique in order to test the EHTS. The first study used quarterly data for 12 US Treasury Bill rates over the period 1960:1-1991:2, while the second study used monthly data for German spot rates for two different samples (1986:1-1998:12 and 1972:9-1998:12). Both of these studies reported evidence in favour of the EHTS. The third study used Canadian end-of-the-month closing yields and forward rates for the period 1988:8-1998:6 and strongly rejected the expectations hypothesis.

Even though most of the studies to date have been concerned with testing the EHTS for a specific country or group of countries, the decomposition of the term structure into its transitory (i.e. the $I(0)$ cointegration) and permanent (i.e. the $I(1)$ common trend) components can be equally useful and insightful. The cointegration relation, which captures the spread between the long and short rates, contains information about the effects of short run monetary policies, while the common trend contains information about long run macroeconomic conditions and expectations about the course of future government policies. The interdependence among the transitory or the permanent components for a group of countries can thus reveal information about the degree of policy convergence among the countries. This is useful information for applied economists and policy makers.

Hafer, Kutan and Zhou (1997) used the multivariate cointegration and common trends techniques of Gonzalo 
and Granger (1995) to study linkages in the term structures of interest rates in 4 EU countries: Belgium, France, Germany and the Netherlands. Using a sample of monthly observations from 1979:3 to 1995:6, they found that the EHTS holds for these countries. Also, by decomposing each term structure into its transitory and permanent components, these authors found that the long term interest rate is the source of the common trend in each country, and that the common trends are cointegrated across countries and thus move together over time, but no single country dominates the common trends. Holmes and Pentecost (1997) reported similar results for 6 EU countries (Belgium, France, Germany, Italy, the Netherlands and the UK), using a sample of monthly observations from 1974:1 to $1996: 3$.

In the present paper we contribute to the existing literature in three ways. First, we use the most recent data available from the early 1990s to the present and the VECM approach of Johansen (1988, 1991, 1994, 1995) to test the EHTS of interest rates for the 10 new EU member states, as well as Bulgaria and Romania that hope to join the EU in 2007.

Second, we use the Gonzalo-Granger methodology to identify and estimate the common trend that drives the cointegrating relation between long and short rates in each country. Hypothesis testing in this framework provides information as to which interest rate contains the common trend. This is useful information for the design of monetary policies of the 10 new EU countries and the 2 prospective member states.

Third, using multivariate Granger causality and Johansen cointegration tests, we investigate the possibility of short run and long run interdependence among the term structures of the countries in our sample. This is also useful information, since interdependence among the term structures of interest rates means interdependence among the monetary policies of these countries.

The rest of the paper is organized as follows. In Section 2 we briefly describe the EHTS of interest rates and outline the models for cointegration and common trends that we use in the paper. In Section 3 we describe the data and analyze the empirical results. Briefly, the evidence suggests that the EHTS holds for all countries of our sample, except for Malta. Our results also indicate that the short run monetary policies are set independently for most of the new EU countries, while the long run monetary policies are only weakly interdependent. Further, our findings indicate strong short run and long run linkages between the monetary policies of Bulgaria and Romania. In Section 4 we make some concluding remarks. 


\section{Theoretical Framework}

\subsection{The EHTS of Interest Rates}

The EHTS of interest rates states that the yield to maturity of an $n$-period bond $R_{n, t}$ will equal an average of the current and future rates on a set of $m$-period short yields $r_{m, t}$, with $m<n$, plus the term premium. The relationship can be expressed in the following form

$$
\left(1+R_{n, t}\right)^{n}=\varphi_{n, t}^{*} \prod_{i=0}^{n-1}\left(1+E_{t} r_{m, t+i}\right)
$$

where $\varphi_{n, t}^{*}$ is a possible non-zero but stationary $n$-period term premium and $E_{t}$ is the expectations operator conditional on information up to and including time $t$. The equality in equation (1) is established by the condition of no arbitrage opportunities to investors willing to hold both short term and long term bonds. Log-linearizing equation (1) we get

$$
R_{n, t}=\varphi_{n, t}+(1 / n) \sum_{i=0}^{n-1} E_{t} r_{m, t+i}
$$

where $\varphi_{n, t}=\log \left(\varphi_{n, t}^{*}\right)$. Equation (2) indicates that the yield of the $n$-period bond and the $m$-period short yields are functionally related. For the subsequent analysis it is convenient to re-express equation (2) as

$$
R_{n, t}-r_{m, t}=\varphi_{n, t}+(1 / n) \sum_{i=1}^{n} E_{t}\left(r_{m, t+i-1}-r_{m, t}\right) .
$$

The left hand side of equation (3) represents the spread between the $n$-period (long term) yield and the $m$-period (short term) yield. Assuming that the yields are $I(1)$ and cointegrated the right hand side of equation (3) is stationary. It follows that the left hand side of equation (3) is stationary and that $(1,-1)^{\prime}$ is a cointegration vector linking the long term and short term interest rates. In what follows, we analyze the time series and cointegration properties of the long term and short term interest rates, given the insights of equation (3).

\subsection{The Cointegration and Common Trends Models}

This section outlines the basic maximum likelihood theory of cointegration and the models that employed in the subsequent empirical analysis. The maximum likelihood theory of cointegration assumes that the stochastic variables are integrated of order one, or $I(1)$, and that the data generating process is a Gaussian ${ }^{1}$ vector autoregressive

\footnotetext{
${ }^{1}$ The Gaussian assumption is not necessary, but it is convenient for the derivation of asymptotic results.
} 
model of finite order $k$, or $V A R(k)$ which may possibly include some deterministic components. Let $Y_{t}$ be a $p$-dimensional column vector of $I(1)$ variables. Then the $V A R(k)$ can be written in a vector error-correction model (VECM) form as

$$
\Delta Y_{t}=\Pi Y_{t-1}+\sum_{i=1}^{k-1} \Gamma_{i} \Delta Y_{t-i}+\mu_{0}+\mu_{1} t+\epsilon_{t}, \quad t=1 \ldots T
$$

where $\Pi$ and $\Gamma_{i}$ are $p \times p$ matrices of coefficients, $\mu_{0}$ and $\mu_{1}$ are $p \times 1$ vectors of constant and trend coefficients, respectively and $\epsilon_{t}$ is a $p \times 1$ multivariate normal random error vector with mean vector zero and variance matrix $\Omega$ that is independent across time periods.

The hypothesis of cointegration can be stated in terms of the rank of the long run matrix $\Pi$ in equation (4). Under the hypothesis of cointegration, this matrix can be written as

$$
\Pi=\alpha \beta^{\prime}
$$

where $\alpha$ and $\beta$ are $p \times r$ matrices of full rank. If $r=0$, then $\Pi=0$, which means that there is no linear combination of the elements of $Y_{t}$ that is stationary. The other extreme case is when the rank of the $\Pi$ matrix equals $p$. In this case $Y_{t}$ is a stationary process. In the intermediate case, when $0<r<p$ there are $r$ stationary linear combinations of the elements of $Y_{t}$ and $p-r$ non stationary common trends.

Under the hypothesis $\Pi=\alpha \beta^{\prime}$, the relation between $\alpha$ and the deterministic term $\mu_{t} \equiv \mu_{0}+\mu_{1} t$ is crucial for the properties of the process $Y_{t}$. To see this, first decompose $\mu_{0}$ and $\mu_{1}$ in the directions of $\alpha$ and $\alpha_{\perp}$, where $\alpha_{\perp}$ is a $p \times(p-r)$ matrix that is the orthogonal complement to $\alpha$ :

$$
\mu_{i}=\alpha \beta_{i}+\alpha_{\perp} \gamma_{i}, \quad i=0,1
$$

where $\beta_{i}=\left(\alpha^{\prime} \alpha\right)^{-1} \alpha^{\prime} \mu_{i}$ and $\gamma_{i}=\left(\alpha_{\perp}^{\prime} \alpha_{\perp}\right)^{-1} \alpha_{\perp}^{\prime} \mu_{i}$. Next, following Johansen (1994), consider the following five submodels, which are ordered from the most to the least restrictive:

Model 0: $\mu_{t}=0$

Model $1^{*}: \mu_{t}=\alpha \beta_{0}$

Model 1: $\mu_{t}=\alpha \beta_{0}+\alpha_{\perp} \gamma_{0}$

Model $2^{*}: \mu_{t}=\alpha \beta_{0}+\alpha_{\perp} \gamma_{0}+\alpha \beta_{1} t$

Model 2: $\mu_{t}=\alpha \beta_{0}+\alpha_{\perp} \gamma_{0}+\left(\alpha \beta_{1}+\alpha_{\perp} \gamma_{1}\right) t$

The interpretation of these models becomes clear in the context of the solution of $Y_{t}$ in equation (4). The 
solution is given by

$$
Y_{t}=C \sum_{i=1}^{t} \epsilon_{t}+\frac{1}{2} \tau_{2} t^{2}+\tau_{1} t+\tau_{0}+W_{t}+A
$$

where $W_{t}$ is a stationary process, $A$ is a vector such that $\beta^{\prime} A=0, C=\beta_{\perp}\left(\alpha_{\perp}^{\prime} \Gamma \beta_{\perp}\right)^{-1} \alpha_{\perp}^{\prime}, \Gamma=I_{p}-\sum_{i=1}^{k-1} \Gamma_{i}, \beta_{\perp}$ is a $p \times(p-r)$ matrix of full rank that is orthogonal to $\beta$ and $\tau_{2}=C \mu_{1}$.

Using equation (7), Johansen (1994) shows that the five submodels imply different behavior for the process $Y_{t}$ and the cointegrating relations $\beta^{\prime} Y_{t}$. Briefly, in Model $0, Y_{t}$ has no deterministic trend and all the stationary components have zero mean. In Model $1^{*}, Y_{t}$ has neither quadratic or linear trend. However, both $Y_{t}$ and the cointegrating relations $\beta^{\prime} Y_{t}$ are allowed a constant term. In Model 1, $Y_{t}$ has a linear trend, but the cointegrating relations $\beta^{\prime} Y_{t}$ have no linear trend. In Model $2^{*}, Y_{t}$ has no quadratic trend but $Y_{t}$ has a linear trend that is present even in the cointegrating relations. In Model $2, Y_{t}$ has a quadratic trend but the cointegrating relations $\beta^{\prime} Y_{t}$ have only a linear trend.

Because of the normality assumption, one can easily test for the reduced rank of the $\Pi$ matrix using the maximum likelihood approach. This procedure gives at once the maximum likelihood estimators (MLE) of $\alpha$ and $\beta$ and the eigenvalues needed in order to construct the likelihood ratio test. The MLE of $\alpha$ and $\beta$ are obtained by regressing $\Delta Y_{t}$ and $Y_{t-1}$ on $\Delta Y_{t-1} \ldots \Delta Y_{t-k}$ and $\mu_{t}$ (allowing for the restrictions imposed by each of the five models). These auxiliary regressions give residuals $R_{0 t}$ and $R_{1 t}$ respectively, and residual product matrices

$$
S_{i j}=T^{-1} \sum_{t=1}^{T} R_{i t} R_{j t}^{\prime}, \quad i, j=0,1
$$

Solving the eigenvalue problem

$$
\left|\lambda S_{11}-S_{10} S_{00}^{-1} S_{01}\right|=0
$$

for eigenvalues $1>\widehat{\lambda}_{1}>\ldots>\widehat{\lambda}_{p}>0$ and eigenvectors $\widehat{V}=\left(\widehat{v}_{1} \ldots \widehat{v}_{p}\right)$, normalized such that $\widehat{V}^{\prime} S_{11} \widehat{V}=I$, one gets the MLE of $\alpha$ and $\beta$ as $\widehat{\alpha}=S_{01} \widehat{\beta}$ and $\widehat{\beta}=\left(\widehat{v}_{1} \ldots \widehat{v}_{r}\right)$, where $\left(\widehat{v}_{1} \ldots \widehat{v}_{r}\right)$ are the eigenvectors associated with the $r$ largest eigenvalues of equation (9).

In testing the null hypothesis that $\operatorname{rank}(\Pi) \leq r$ against the alternative hypothesis that $\operatorname{rank}(\Pi)=p$, the likelihood ratio statistic, called also the Trace statistic by Johansen and Juselius (1990), is given by

$$
\text { Trace }=-T \sum_{i=r+1}^{p} \ln \left(1-\widehat{\lambda}_{i}\right)
$$

The testing is performed sequentially for $r=0, \ldots, p-1$ and it terminates when the null hypothesis is not rejected 
for the first time.

It is also possible to test the null hypothesis that $\operatorname{rank}(\Pi)=r$ against the alternative that $\operatorname{rank}(\Pi)=r+1$. In this case, the likelihood ratio statistic, which is called the $\lambda_{\max }$ statistic, is given by

$$
\lambda_{\max }=-T \ln \left(1-\widehat{\lambda}_{r+1}\right)
$$

Of course, the $\lambda_{\max }$ statistic is equal to the Trace statistic when $p-r=1$.

MacKinnon, Haug and Michelis (1999) have computed highly accurate critical values for the Trace statistic in equation (10) and the $\lambda_{\max }$ statistic in equation (11), using the response surface methodology. These critical values differ substantially from those in the existing literature, especially when the dimension of the VECM is large; e.g., see Osterwald-Lenum (1992) or Johansen (1995). Since we deal with large dimensional systems in this study, we use these new critical values for testing hypotheses ${ }^{2}$.

In respect to the common trends, it is clear from equation (7) that the common trends in $Y_{t}$ are contained in the first term of that expression. Given the definition of $C$, Johansen (1995, p. 41) defines the common trends by the cumulated disturbances $\alpha_{\perp}^{\prime} \sum_{i=1}^{t} \epsilon_{t}$. Assuming that the common trends are a linear combination of $Y_{t}$, in the form $f_{t}=\alpha_{\perp}^{\prime} Y_{t}$, Gonzalo and Granger (1995) derived the MLE of $\alpha_{\perp}$ as the eigenvectors corresponding to the $(p-r)$ smallest eigenvalues of the problem

$$
\left|\lambda S_{00}-S_{01} S_{11}^{-1} S_{10}\right|=0
$$

Solving equation (12) for eigenvalues $1>\widehat{\lambda}_{1}>\ldots>\widehat{\lambda}_{p}>0$ and eigenvectors $\widehat{M}=\left(\widehat{m}_{1} \ldots \widehat{m}_{p}\right)$, normalized such that $\widehat{M}^{\prime} S_{00} \widehat{M}=I$, one gets the MLE of $\alpha_{\perp}$ as $\widehat{\alpha}_{\perp}=\left(\widehat{m}_{r+1} \ldots \widehat{m}_{p}\right)$.

Given this framework, it is easy to test whether or not certain linear combinations of $Y_{t}$ can be common trends. Null hypotheses on $\alpha_{\perp}$ have the following form

$$
H_{0}: \alpha_{\perp}=G \theta
$$

where $G$ is a $p \times m$ known matrix of constants and $\theta$ is an $m \times(p-r)$ matrix of unknown coefficients such that $p-r \leq m \leq p$. To carry out the test, one solves the eigenvalue problem

$$
\left|\lambda G^{\prime} S_{00} G-G^{\prime} S_{01} S_{11}^{-1} S_{10} G\right|=0
$$

\footnotetext{
${ }^{2}$ The latest edition of EViews 5 has also adopted the MacKinnon et al.(1999) critical values.
} 
for eigenvalues $1>\widehat{\lambda}_{1}^{*}>\ldots>\widehat{\lambda}_{m}^{*}>0$, and eigenvectors $\widehat{M}^{*}=\left(\widehat{m}_{1}^{*} \ldots \widehat{m}_{m}^{*}\right)$, normalized such that $\widehat{M}^{* \prime}\left(G^{\prime} S_{00} G\right) \widehat{M}^{*}=$ I. Choose $\widehat{\theta}_{m \times(p-r)}=\left(\widehat{m}_{(m+1)-(p-r)} \ldots \widehat{m}_{m}\right)$ and $\widehat{\alpha}_{\perp}=G \widehat{\theta}$. The likelihood ratio test statistic for testing $H_{0}$ is given by

$$
L=-T \sum_{i=r+1}^{p} \ln \left[\left(1-\widehat{\lambda}_{i+(m-p)}^{*}\right) /\left(1-\widehat{\lambda}_{i}\right)\right]
$$

In the next section, we use the $L$-statistic in (15) to test the statistical significance of the $\alpha_{\perp}$ of the long term and the short term interest rate of the EU accession countries. A significant $\alpha_{\perp}$ implies that the respective interest rate is weakly exogenous and dominates the common trend in the cointegrating system.

\section{$3 \quad$ Data and Empirical Results}

\subsection{Data}

We collected data for the 10 new EU countries and for the 2 prospective EU countries, Bulgaria and Romania. Due to lack of data availability we worked only on two interest rates for each country: either treasury bill yields (short term) and government bond yields (long term) or short term and long term commercial banks' lending rates. Our sample consists of monthly data of varying time spans for different countries determined by data availability. All interest rates are expressed in natural logarithms.

For Cyprus the time span is 1997:1 to 2004:12. Monthly average treasury bill rates were obtained from line 60c of the CD-ROM of the International Financial Statistics (IFS) of the IMF, 2004. Monthly average government bond yields were obtained from the Central Bank of Cyprus and refer to bonds with maturity greater than 5 years. For the Czech Republic the time span is 1993:8 to 2004:12. Treasury bill rates were taken from line 60c of the IFS. Long term government bond yields were obtained from line 61 of the IFS. This IFS data series begins at January 2000. For the period 1993:8-1999:12 we used long term government bond yields obtained from the Central Bank of the Czech Republic.

No data on treasury bill rates or government bond yields are available for Estonia, Latvia, Lithuania and Slovenia. For this reason, we used commercial banks' lending rates instead. For Estonia the time span is 1994:1 to 2004:12. Three-month lending rates were obtained from the Main Economic Indicators (MEI) of the OECD, 2004, and 10-year lending rates were taken from the Central Bank of Estonia. For Latvia short term and long term lending rates were obtained from the MEI and the time span is 1993:1 to 2004:12. For Lithuania 6 to12 months and over 5 years lending rates were taken from the Central Bank of Lithuania and the time span is 1997:1 to 2004:12. 
For Slovenia the time span is 1996:1 to 2004:12 and the short term and long term lending rates were obtained from the Central Bank of Slovenia.

For Hungary the time span is 1997:1 to 2004:12. The 3-month treasury bill rates and the 5-year government bond yields were obtained from the Central Bank of Hungary. For Malta the time span is 1993:1 to 2004:12. Monthly average treasury bill rates were obtained from line 60c of the IFS, while 5-year monthly average government bond yields were taken from the Central Bank of Malta.

For Poland the time span is 1994:2 to 2004:12. The 1-year treasury bill rates and the over 2 years government bond yields were obtained from the Polish Ministry of Finance. In the case of the Slovak Republic the time span is 1994:12 to 2004:12. The 1 to 6 months treasury bill rates were taken from the Central Bank of the Slovak Republic. For government bond yields the IFS data series (line 61) for the Slovak Republic begins at September 2000 and refers to 10-year government bond yields. For the period 1994:12-2000:8 we collected data from the Central Bank of the Slovak Republic.

For Bulgaria the time span is 1993:7 to 2004:12. Monthly average treasury bill rates were obtained from the Central Bank of Bulgaria and monthly average government bond yields were obtained from line 61 of the IFS. For Romania the time span is 1997:1 to 2004:12. Since data for treasury bill rates and government bond yields are not available, we used long term and short term lending rates that were taken from the MEI. The MEI data series ends at December 2003. For the period 2004:1-2004:12 we used long term and short term lending rates obtained from the Central Bank of Romania.

\subsection{Testing for the EHTS}

In this section we report and analyze the unit root and cointegration results between the short term and the long term interest rates for each country. Evidence of cointegration would validate empirically the EHTS of interest rates.

Before testing for cointegration, we tested each time series for unit roots using the Augmented Dickey-Fuller test at the 5 percent level of significance. The results are presented in Table 1 . To select the appropriate lag length for the ADF test regression, we used the Akaike's information criterion. As shown in Table 1, we fail to reject the unit root hypothesis in the long and short rates in all countries except Poland. In all the cases where the unit root hypothesis was not rejected, we also tested for a second unit root. As shown in Table 1, this hypothesis was rejected in all cases. Based on these results we proceeded with cointegration analysis using the VECM in equation (4) above, where $Y_{t}=\left(R_{n, t}, r_{m, t}\right)^{\prime}$. 
To select the appropriate lag length, $k$, in equation (4), we set up a separate VECM for each country and used the likelihood ratio test. Under the hypothesis $\Gamma_{k}=0$, the likelihood ratio test is asymptotically distributed as $\chi^{2}$ with $p^{2}$ degrees of freedom (see Johansen 1995, p. 21). Further, to determine which submodel describes best each set of variables, we tested the submodels against each other using the likelihood ratio tests in Johansen (1995, Chapter 11, Corollary 11.2 and Theorem 11.3, pp. 161-162). These tests are also distributed as $\chi^{2}$ with degrees of freedom determined by the pairs of models being tested as follows:

$$
0 \underset{r}{\subset} 1^{*} \underset{p-r}{\subset} 1 \underset{r}{\subset} 2^{*} \underset{p-r}{\subset} 2
$$

Table 2 reports the cointegration results between the long and short rates for each of the new EU countries (except Poland) plus Bulgaria and Romania. Based on the Trace and the $\lambda_{\max }$ statistics at the 5 percent level of significance, we find evidence of one cointegrating vector between the short term and the long term interest rates in all the countries, except Malta. Clearly, this is indirect evidence in favour of the EHTS of interest rates in all countries in this sample, except for Malta.

Table 3 reports the parameter estimates of the cointegration vectors, normalized on the long rate, for the countries for which the EHTS holds (i.e. Cyprus, the Czech Republic, Estonia, Hungary, Latvia, Lithuania, the Slovak Republic, Slovenia, Bulgaria and Romania). Numbers in parentheses are likelihood ratio test statistics which are distributed as $\chi_{1}^{2}$ asymptotically, under the null hypothesis that each component of the cointegration vector is insignificantly different from zero. As shown in Table 3 , the parameters of the cointegrating vectors $\left(\beta_{i}\right.$ 's) are statistically significant in all cases, which means that the short term and the long term interest rates enter significantly each cointegration vector. We also tested the hypothesis $H_{0}: \beta_{R}+\beta_{r}=0$, when $\left(\beta_{R}, \beta_{r}\right)=(1,-1)$. Equivalently, we tested whether or not the spread between the long term and short term interest rates belongs in the cointegration space of the term structure, as suggested by the EHTS. Using the likelihood ratio test statistic at the 5 percent level of significance, this hypothesis is rejected for Cyprus, the Czech Republic, Hungary, Latvia, Slovenia, Bulgaria and Romania, but it cannot not be rejected for Estonia, Lithuania and the Slovak Republic. Consequently, only the latter group of countries satisfy the EHTS exactly.

The parameter estimates of the adjustment coefficients $\alpha_{R}$ and $\alpha_{r}$ are also presented in Table 3. These are the coefficients of the error correction terms in the VECM and their subscripts denote the variable that adjusts to deviations from the long run equilibrium relation between the two rates. As shown in Table $3, \alpha_{R}$ is statistically significant and $\alpha_{r}$ is statistically insignificant at the 5 percent level, for the three Baltic countries (i.e., Estonia, Latvia and Lithuania) and for Romania. This implies that, for this group of countries, the long term interest rate is 
an endogenous variable which adjusts to deviations from its long run equilibrium with the short rate. At the same time, the short rate is a weakly exogenous variable, changes of which have a permanent effect on both the long rate and the short rate. On the other hand, $\alpha_{R}$ is statistically insignificant and $\alpha_{r}$ is statistically significant for Cyprus, the Czech Republic, Hungary, the Slovak Republic, Slovenia and Bulgaria. Hence for the latter group of countries, the evidence suggests that the short term interest rate adjusts to deviations from the long run equilibrium, while the long rate is weakly exogenous, affected primarily by fundamental factors such as the future state of the economy and expectations about the future path of government policies.

These empirical findings are reinforced by direct tests on the $\alpha_{\perp}$ 's, the components of the common trend in each country. In order to test the statistical significance of the the $\alpha_{\perp}$ 's, we compute the $L-$ statistic in equation (15) for specific choices of the $G$ matrix. In particular, to test the null hypothesis that the long term interest rate has a permanent component in the common trend of a country, we set the $G$ matrix to

$$
G=\left[\begin{array}{l}
1 \\
0
\end{array}\right]
$$

Alternatively, to test the hypothesis tat the short term interest rate has a permanent component in the common trend, we set the $G$ matrix to

$$
G=\left[\begin{array}{l}
0 \\
1
\end{array}\right]
$$

Table 3 reports the computed $L$-statistics. For the countries for which $\alpha_{R}$ is statistically significant (i.e., the three Baltic countries and Romania), the null hypothesis that the short term interest rate, $r$, has a permanent component in the common trend cannot be rejected at the 5 percent level of significance.

On the other hand, for the countries with a significant $\alpha_{r}$ (i.e. Cyprus, the Czech Republic, Hungary, the Slovak Republic, Slovenia and Bulgaria), the null hypothesis that the long term interest rate, $R$, has a permanent component in the common trend cannot be rejected at the 5 percent level of significance. For these countries the short term interest rate adjusts to deviation from the long run equilibrium, while the long term interest rate is not affected by past disequilibria and thus "drives" the common trend. 


\subsection{Short Run Interdependence}

In this section we analyze short run interdependence among the term structures of the new EU member states, using Granger causality tests. In order to include all the countries in our analysis, the time span is restricted to 1997:1- 2004:12, in this and the next section. Poland is also included in the analysis of this section as its interest rates and their spread are stationary variables.

Fluctuations in the transitory component (or the spread) of the term structure are often thought to be caused by changes in monetary policy. If these fluctuations are related across the countries, then it is possible that policy actions are interdependent in the short run. Since the transitory components of the term structures are stationary, we test for such interdependence explicitly by conducting Granger-causality tests based on multivariate VAR models among the cointegrating relations. The appropriate lag length for each VAR model was selected using the likelihood ratio test.

The causality results are reported in Table 4 . The tests results contain pairwise causality tests and joint causality tests that include all the countries in a given group of countries. The first panel of Table 4 includes results for all the new EU member states, except Malta. Malta was excluded from this analysis, since its interest rates do not cointegrate. It is clear from this panel that there is weak short run interdependence among the term structures of the countries in this group. Only 5 out of 72 possible pairwise test statistics (excluding the own effects) and 2 out of 9 joint test statistics (including only the cross effects) are significant at the 5 or 10 percent level of significance. For example, only the Estonia's spread is influenced by changes in the spreads of the Czech Republic and Poland, both pairwise and jointly. Similar results hold for Slovenia with respect to the Slovak Republic.

The second panel of Table 4 reports the results for the group of the Eastern European countries: the Czech Republic, Hungary, Poland, the Slovak Republic and Slovenia. In this case, there is also evidence of loose short run linkages among the term structures. The Wald test statistics are significant in 5 out of 20 pairwise tests and 2 out of 5 joint tests. Changes in the spreads of the other Eastern European countries jointly influence only those of the Slovak Republic and Slovenia in the short run. These findings are expected, given relative independence of the Czech Republic, Hungary and Poland, which in recent times have followed policies tied more closely to Western Europe than to Eastern Europe.

The third panel of Table 4 includes the three Baltic countries. As shown in the second column of this panel, change in the spread of Estonia affects the spread of Latvia at the 5 percent level of significance. The spread of Estonia is unaffected by changes in the spread of Latvia and Lithuania. The same result holds for Lithuania with respect to Estonia and Latvia. Clearly, the term structures of the three Baltic countries are minimally linked to 
each other, which reflects their independent monetary policies.

The last panel of Table 4 refers to Bulgaria and Romania, which hope to become EU members by 2007 . In this case, the empirical results indicate strong short run interdependence, both pairwise and jointly, between the term structures of these two countries. The Wald test statistics are significant at the 5 percent level of significance for both countries. This evidence may reflect the historic, economic and political ties between the two countries, as well as their joint efforts, in recent times, to become ready to join the EU.

In summary, the above results indicate weak short run linkages among the term structures of the new EU countries including the sub-groups of the 5 Eastern European countries and the Baltic countries. The results also indicate stronger short run linkages between the term structures of Bulgaria and Romania.

\subsection{Long Run Interdependence}

In this section, we examine the long run interdependence among the term structures, by analyzing linkages among their common trends in a cointegration framework.

The common trends are often thought to capture information about future economic and monetary policies. Following Hafer and Kutan (1994) we can claim that there are strong long run linkages among these policies in a group of $p$ countries, if there exist $r=p-1$ cointegrating relations among the common trends. On the other hand, if $0<r<p-1$, then there is only partial interdependence among the future policies of the countries concerned. In this sense, interdependence means that the countries' policies have converged enough, so that the permanent components of their term structures tend to move towards a long run equilibrium and do not drift too far apart over time.

The cointegration results for the common trends for different groups of countries are reported in Table $5^{3}$. The Trace and $\lambda_{\max }$ statistics refer to the same groups of countries as in the previous section ${ }^{4}$. As shown in the first panel of Table 5 , the Trace and the $\lambda_{\max }$ statistics indicate four and three cointegration vectors respectively, at the 5 percent significance level, among the eight common trends of the new EU countries. For the four Eastern European countries, both statistics indicate one cointegration vector among the four common trends. Similarly for the three Baltic countries, both statistics indicate one cointegration vector among the three common trends. Overall, the above results indicate weak long run interdependence among the term structures in these groups of countries, and consequently, only partial long run convergence of their monetary policies.

\footnotetext{
${ }^{3}$ The appropriate lag length $k$ for the VECM and the sub-model that describes best each set of variables were chosen following the same procedures as in Section 3.2 above.

${ }^{4}$ Poland was not included in this section, since its interest rates are stationary.
} 
The last panel of Table 5 reports the results for Bulgaria and Romania. Both statistics indicate one cointegration vector between the two common trends, at the 5 percent level of significance. These results point to strong long run linkages between the term structures and monetary policies of these two countries. This evidence is encouraging as these two countries aspire to become EU members in 2007.

The results for Bulgaria and Romania seem plausible. Since the mid-1990s, both countries have implemented radical programs of structural reforms and macroeconomic stabilization. Their budgetary discipline and privatization programs have helped to stabilize their public deficits. They have also managed to reduce inflation gradually and stabilize their nominal exchange rates. Bulgaria adopted a currency board arrangement for its exchange rate, while Romania controlled tightly its monetary base. All these policy measures are reflected, in turn, in the evidence of interdependence between their term structures.

\section{Concluding Remarks}

In this paper we investigated empirically the term structure of interest rates among the 10 new and 2 prospective EU countries. Since the interest rates follow random walks, we evaluated the expectations hypothesis of the term structure using cointegration analysis and common trends techniques. Further we analyzed short run and long run interdependence among the term structures of these countries.

Our empirical findings indicate that the EHTS holds for all the new EU countries, except for Malta. For Cyprus, the Czech Republic, Hungary, the Slovak Republic, Slovenia and Bulgaria, the long term interest rate is weakly exogenous and drives the common trend in each term structure. On the other hand, for the three Baltic countries and Romania, the short term interest rate is weakly exogenous and has a permanent component in the common trend.

Our results also indicate weak short run and long run interdependence among the term structures of the new EU states and the subgroups of the Eastern European and the Baltic countries. This evidence, in turn, implies that these countries set their monetary policies independently, both in the short run and the long run.

Only the two prospective EU countries of Bulgaria and Romania appear to have interdependent term structures pointing to strong short run and long run interdependence between their monetary policies. These strong linkages will contribute positively in their efforts to join the EU easier in 2007.

Our analysis has been focused on term structure linkages among the new and the two prospective EU countries. This is a useful exercise as it provides valuable knowledge about the degree of monetary convergence in these countries. More insights can be gained by analyzing the term structures of these countries in relation to some core 
EU countries such as France and Germany. We intend to undertake this research in the near future. 


\section{References}

Anatolyev, S. and Korepanov, S. (2003) The term structure of Russian interest rates, Applied Economics Letters, 10, 867-70.

Balcombe, K. and Tiffin, R. (2002) Bootstrap testing of the expectations hypothesis with the term structure of interest rates, Applied Economics Letters, 9, 563-6.

Cassola, N. and Luis, J.B. (2003) A two factor model of the German term structure of interest rates, Applied Financial Economics, 13, 783-806.

Chen, L.-H. (2001) Inflation and real short-term interest rates - A Kalman filter analysis of the term structure, Applied Economics, 33, 855-61.

Dominguez, E. and Novales, A. (2002) Can forward rates be used to improve interest rate forecasts?, Applied Financial Economics, 12, 493-504.

Gerlach, S. and Smets, F. (1997) The term structure of Euro-rates: some evidence in support of the expectations hypothesis, Journal of International Money and Finance, 16, 305-21.

Gonzalo, J. and Granger, C.W.J. (1995) Estimation of common long-memory components in cointegrated systems, Journal of Business and Economic Statistics, 13, 27-35.

Gravelle, T. and Morley, J.C. (2005) A Kalman filter approach to characterizing the Canadian term structure of interest rates, Applied Financial Economics, 15, 691-705.

Hafer, R.W. and Kutan, A.M. (1994) A long run view of German dominance and the degree of policy convergence in the EMS, Economic Inquiry, 32, 684-95.

Hafer, R.W., Kutan, A.M. and Zhou, S. (1997) Linkages in the EMS term structures: evidence from common trend and transitory components, Journal of International Money and Finance, 16, 595-607.

Hall, A.D., Anderson, H.M. and Granger, C.W.J. (1992) A cointegration analysis of treasury bill yields, Review of Economics and Statistics, 74, 116-26.

Hardouvelis, G.A. (1994) The term structure spread and future changes in long and short rates in the G7 countries, Journal of Monetary Economics, 33, 255-83. 
Holmes, M.J. and Pentecost, E.J. (1997) The term structure of interest rates and financial integration in the ERM, International Journal of Finance and Economics, 2, 237-47.

International Monetary Fund, (2004) International Financial Statistics (IFS) CD-ROM, International Monetary Fund, Washington DC.

Johansen, S. (1988) Statistical analysis of cointegration vectors, Journal of Economic Dynamics and Control, 12, $231-54$.

Johansen, S. (1991) Estimation and hypothesis testing of cointegration in Gaussian vector autoregressive models, Econometrica, 59, 1551-80.

Johansen, S. (1994) The role of the constant and linear terms in cointegration analysis of nonstationary variables, Econometric Reviews, 13, 205-29.

Johansen, S. (1995) Likelihood-based Inference in Cointegrated Vector Autoregressive Models, Oxford University Press, Oxford.

Johansen, S. and Juselius, K. (1990) Maximum likelihood estimation and inference on cointegration with applications to the demand for money, Oxford Bulletin of Economics and Statistics, 52, 169-210.

MacKinnon, J.G., Haug, A.A. and Michelis, L. (1999) Numerical distribution functions of likelihood ratio tests for cointegration, Journal of Applied Econometrics, 14, 563-77.

McDermott, C.J. (1998) Testing the expectations model of the term structure in times of financial transition, Applied Financial Economics, 8, 663-9.

OECD, (2004) Main Economic Indicators, OECD, Paris.

Osterwald-Lenum, M. (1992) A note with quantiles of the asymptotic distribution of the maximum likelihood cointegration rank test statistics, Oxford Bulletin of Economics and Statistics, 54, 461-71.

Shiller, R.J. (1990) The term structure of interest rates, in Handbook of Monetary Economics, Vol. 1 (Eds) B.M. Friedman and F.H. Hahn, North-Holland, Amsterdam, pp. 627-722.

Wolters, J. (1998) Cointegration and German bond yields, Applied Economics Letters, 5, 497-502. 
Table 1

Augmented Dickey - Fuller tests for a unit root ${ }^{\mathrm{a}}$

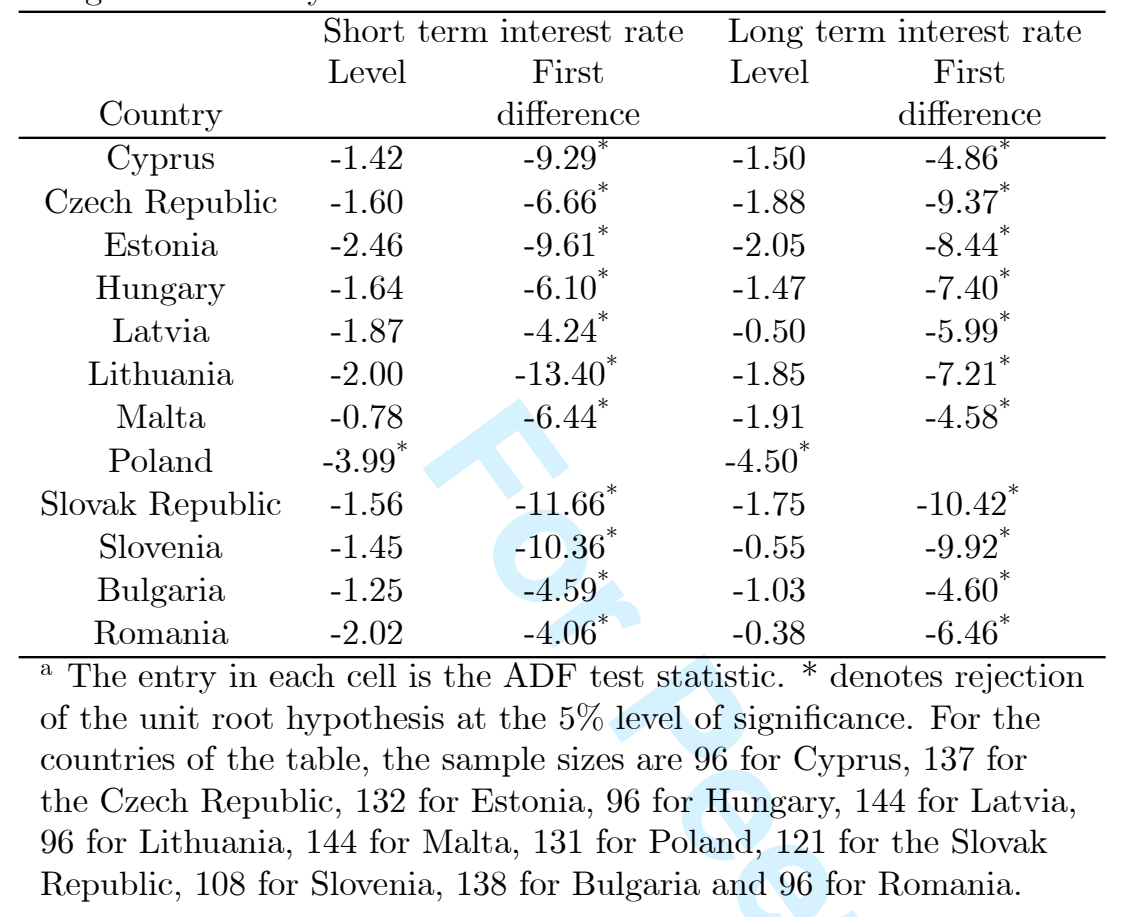


Table 2

Trace and $\lambda_{\max }$ statistics

\begin{tabular}{|c|c|c|c|c|c|c|c|c|c|c|}
\hline \multirow[b]{2}{*}{$(p-r)$} & \multicolumn{2}{|c|}{ Cyprus } & \multicolumn{2}{|c|}{ Czech Republic } & \multicolumn{2}{|c|}{ Estonia } & \multicolumn{2}{|c|}{ Hungary } & \multicolumn{2}{|c|}{ Latvia } \\
\hline & Trace & $\lambda_{\max }$ & Trace & $\lambda_{\max }$ & Trace & $\lambda_{\max }$ & Trace & $\lambda_{\max }$ & Trace & $\lambda_{\max }$ \\
\hline 2 & $38.23^{*}$ & $38.11^{*}$ & $20.88^{*}$ & $19.67^{*}$ & $17.23^{*}$ & $15.20^{*}$ & $15.09^{*}$ & $13.29^{*}$ & $28.76^{*}$ & $23.30^{*}$ \\
\hline 1 & 0.13 & 0.13 & 1.21 & 1.21 & 2.04 & 2.04 & 1.80 & 1.80 & 5.46 & 5.46 \\
\hline$k^{\mathrm{a}}$ & \multicolumn{2}{|c|}{2} & \multicolumn{2}{|c|}{3} & \multicolumn{2}{|c|}{3} & \multicolumn{2}{|c|}{2} & \multicolumn{2}{|c|}{6} \\
\hline Model & \multicolumn{2}{|c|}{0} & \multicolumn{2}{|c|}{$1^{*}$} & \multicolumn{2}{|c|}{0} & \multicolumn{2}{|c|}{0} & \multicolumn{2}{|c|}{$1^{*}$} \\
\hline & \multicolumn{2}{|c|}{ Lithuania } & \multicolumn{2}{|c|}{ Malta } & \multicolumn{2}{|c|}{ Slovak Republic } & \multicolumn{2}{|c|}{ Slovenia } & \multicolumn{2}{|c|}{ Bulgaria } \\
\hline$(p-r)$ & Trace & $\lambda_{\max }$ & Trace & $\lambda_{\max }$ & Trace & $\lambda_{\max }$ & Trace & $\lambda_{\max }$ & Trace & $\lambda_{\max }$ \\
\hline 2 & $21.44^{*}$ & $16.03^{*}$ & 2.86 & 1.75 & $24.99^{*}$ & $24.65^{*}$ & $14.12^{*}$ & $11.75^{*}$ & $22.97^{*}$ & $19.52^{*}$ \\
\hline 1 & 5.41 & 5.41 & 1.11 & 1.11 & 0.34 & 0.34 & 2.37 & 2.37 & 3.44 & 3.44 \\
\hline$k$ & \multicolumn{2}{|c|}{5} & & & \multicolumn{2}{|c|}{3} & \multicolumn{2}{|c|}{4} & \multicolumn{2}{|c|}{3} \\
\hline Model & \multicolumn{2}{|c|}{$1^{*}$} & \multicolumn{2}{|c|}{0} & \multicolumn{2}{|c|}{0} & \multicolumn{2}{|c|}{0} & \multicolumn{2}{|c|}{$1^{*}$} \\
\hline & \multicolumn{2}{|c|}{ Romania } & & & \multicolumn{2}{|c|}{$\begin{array}{l}5 \% \text { critical } \\
\text { values for } \\
\text { Model } 0\end{array}$} & \multicolumn{2}{|c|}{$\begin{array}{l}5 \% \text { critical } \\
\text { values for } \\
\text { Model } 1^{*}\end{array}$} & & \\
\hline$(p-r)$ & Trace & $\lambda_{\max }$ & & & Trace & $\lambda_{\max }$ & Trace & $\lambda_{\max }$ & & \\
\hline 2 & $25.43^{*}$ & $20.32^{*}$ & & & 12.32 & 11.22 & 20.26 & 15.89 & & \\
\hline 1 & 5.11 & 5.11 & & & 4.13 & 4.13 & 9.16 & 9.16 & & \\
\hline$k$ & & & & & & & & & & \\
\hline Model & & & & & & & & & & \\
\hline
\end{tabular}

The value reported at the top of each column is for $r=0$, so that $p-r=p$, where $p=2$

(i.e. the number of interest rates included). ${ }^{*}$ denotes rejection of the null hypothesis of at most $r$ cointegrating relations at the $5 \%$ level of significance. ${ }^{a} k$ indicates the lag length. 
Table 3

Testing for the term structure of interest rates

\begin{tabular}{|c|c|c|c|c|}
\hline & Cyprus & Czech Republic & Estonia & Hungary \\
\hline$\beta_{R}$ & $1.00^{* *}(37.78)$ & $1.00^{* *}(18.33)$ & $\left.1.00^{* *} 12.54\right)$ & $1.00^{* *}(11.43)$ \\
\hline$\beta_{r}$ & $-1.16^{* *}(37.89)$ & $-0.72^{* *}(17.28)$ & $-1.00^{* *}(13.13)$ & $-0.93^{* *}(11.47)$ \\
\hline$H_{0}: \beta_{R}+\beta_{r}=0$ & $37.51^{* *}$ & $14.54^{* *}$ & 0.01 & $9.52^{* *}$ \\
\hline$\alpha_{R}$ & $0.03(0.18)$ & $-0.06(1.16)$ & $-0.09^{* *}(9.66)$ & $-0.10(0.78)$ \\
\hline$\alpha_{r}$ & $0.49^{* *}(37.41)$ & $0.12^{* *}(16.75)$ & $0.09(2.67)$ & $0.23^{*}(3.31)$ \\
\hline$\alpha_{\perp}^{R}$ & -27.58 & -14.67 & $-3.63^{* *}$ & -11.17 \\
\hline$L-$ statistic & 0.18 & 1.16 & 9.66 & 0.78 \\
\hline$\alpha_{\perp}^{r}$ & $1.80^{* *}$ & $-7.09^{* *}$ & -3.75 & $-4.72^{*}$ \\
\hline \multirow{2}{*}{$L-$ statistic } & 37.38 & 16.77 & 2.67 & 3.31 \\
\hline & Latvia & Lithuania & Slovak Republic & Slovenia \\
\hline$\beta_{R}$ & $1.00^{* *}(17.67)$ & $1.00^{* *}(9.42)$ & $1.00^{* *}(23.81)$ & $1.00^{*}(3.41)$ \\
\hline$\beta_{r}$ & $-0.68^{* *}(17.77)$ & $-0.84^{* *}(10.37)$ & $-1.00^{* *}(22.70)$ & $-1.09^{*}(3.83)$ \\
\hline$H_{0}: \beta_{R}+\beta_{r}=0$ & $14.24^{* *}$ & 0.45 & 0.02 & $9.11^{* *}$ \\
\hline$\alpha_{R}$ & $-0.47^{* *}(14.35)$ & $-0.23^{* *}(10.58)$ & $-0.07(2.48)$ & $0.04(2.10)$ \\
\hline$\alpha_{r}$ & $0.13(1.97)$ & $0.01(0.11)$ & $0.14^{* *}(7.79)$ & $0.08^{* *}(7.96)$ \\
\hline$\alpha_{\perp}^{R}$ & $2.41^{* *}$ & $0.78^{* *}$ & -4.81 & -29.16 \\
\hline$L-$ statistic & 14.34 & 10.57 & 2.48 & 2.09 \\
\hline$\alpha_{\perp}^{r}$ & 9.05 & 13.30 & $-2.66^{* *}$ & $13.76^{* *}$ \\
\hline \multirow[t]{2}{*}{$L-$ statistic } & 1.97 & 0.11 & 7.79 & 7.97 \\
\hline & Bulgaria & Romania & & \\
\hline$\beta_{R}$ & $1.00^{* *}(15.44)$ & $1.00^{* *}(14.78)$ & & \\
\hline$\beta_{r}$ & $-0.72^{* *}(15.89)$ & $-0.71^{* *}(13.94)$ & & \\
\hline$H_{0}: \beta_{R}+\beta_{r}=0$ & $13.41^{* *}$ & $14.61^{* *}$ & & \\
\hline$\alpha_{R}$ & $0.02(0.02)$ & $-0.24^{* *}(11.33)$ & & \\
\hline$\alpha_{r}$ & $0.58^{* *}(6.79)$ & $0.05(0.04)$ & & \\
\hline$\alpha_{\perp}^{R}$ & -5.00 & $-1.54^{* *}$ & & \\
\hline$L$-statistic & 0.02 & 11.39 & & \\
\hline$\alpha_{\perp}^{r}$ & $0.02^{* *}$ & -6.90 & & \\
\hline$L-$ statistic & 6.79 & 0.04 & & \\
\hline
\end{tabular}

$R$ and $r$ denote the long term and short term interest rate respectively. The $\beta$ 's are the parameters of the cointegrating vectors, normalized on the long term interest rates. The $\alpha$ 's are the adjustment coefficients and $\alpha_{\perp}$ s are their orthogonal complements. Numbers in parentheses are likelihood ratio statistics for $H_{0}: \beta_{i}=0$ or $H_{0}: \alpha_{i}=0$. Numbers in the row of $H_{0}: \beta_{R}+\beta_{r}=0$ are likelihood ratio test statistics. $L$-statistics are for the null hypothesis that the respective interest rate (either $R$ or $r$ ) determines the common trend. ** $(*)$ denotes rejection of the null hypothesis at the $5 \%(10 \%)$ level of significance. 
Table 4

Testing for short run interdependence: Multivariate Granger Causality tests ${ }^{\mathrm{a}}$

\begin{tabular}{|c|c|c|c|c|c|c|c|c|c|c|}
\hline \multirow{2}{*}{$\begin{array}{c}\text { Dependent } \\
\text { variable }\end{array}$} & \multicolumn{10}{|c|}{ Explanatory variables (lag length $=3$ ) } \\
\hline & $\mathrm{CY}$ & $\mathrm{CZ}$ & $\mathrm{EE}$ & HU & $\mathrm{LV}$ & LT & $\mathrm{PL}$ & SK & SV & Joint \\
\hline $\mathrm{CY}$ & $45.46^{* *}$ & 3.52 & 1.53 & 4.58 & 1.10 & 0.11 & 1.19 & 0.46 & 0.61 & 14.69 \\
\hline $\mathrm{CZ}$ & 5.59 & $76.01^{* *}$ & 3.07 & 2.18 & 1.44 & 2.89 & 1.32 & 4.26 & 3.75 & 21.52 \\
\hline $\mathrm{EE}$ & 5.65 & $13.33^{* *}$ & $17.13^{* *}$ & 1.07 & 1.07 & 2.82 & $11.91^{* *}$ & 3.72 & 3.19 & $33.70^{*}$ \\
\hline $\mathrm{HU}$ & 2.43 & 4.02 & 4.95 & $67.80^{* *}$ & 2.08 & 2.19 & 1.51 & 4.10 & 1.66 & 19.05 \\
\hline LV & 2.19 & 2.13 & 1.49 & 0.43 & $21.34^{* *}$ & 1.26 & $6.45^{*}$ & 1.80 & 0.09 & 19.57 \\
\hline LT & 0.45 & 1.29 & 1.81 & 1.65 & 2.12 & $80.62^{* *}$ & 5.89 & 0.35 & 1.48 & 18.53 \\
\hline $\mathrm{PL}$ & 1.41 & 0.13 & 3.46 & 1.41 & 1.16 & 0.66 & $339.16^{* *}$ & 2.36 & 1.29 & 15.24 \\
\hline SK & 0.93 & 2.97 & $10.38^{* *}$ & 0.20 & 4.02 & 2.26 & 1.43 & $9.71^{* *}$ & 2.12 & 27.82 \\
\hline $\mathrm{SV}$ & 1.13 & 1.60 & 5.40 & 2.96 & 1.03 & 3.44 & 1.17 & $13.80^{* *}$ & $1004.19^{* *}$ & $39.84^{* *}$ \\
\hline$d f^{b}$ & 3 & 3 & 3 & 3 & 3 & 3 & 3 & 3 & 3 & 24 \\
\hline Dependent & \multicolumn{10}{|c|}{ Explanatory variables (lag length $=2$ ) } \\
\hline variable & $\mathrm{CZ}$ & $\mathrm{HU}$ & $\mathrm{PL}$ & SK & SV & & & & & Joint \\
\hline $\mathrm{CZ}$ & $193.59^{* *}$ & 3.31 & 0.12 & 2.81 & 0.27 & & & & & 6.34 \\
\hline HU & 1.21 & $78.27^{* *}$ & 0.05 & 2.34 & 2.91 & & & & & 7.03 \\
\hline $\mathrm{PL}$ & 0.67 & 0.64 & $332.06^{* *}$ & 2.03 & 1.73 & & & & & 6.87 \\
\hline SK & $6.62^{* *}$ & 0.53 & $4.74^{*}$ & $8.94^{* *}$ & $6.63^{* *}$ & & & & & $19.08^{* *}$ \\
\hline SV & $5.87^{*}$ & 2.29 & 3.31 & $12.30^{* *}$ & $126.07^{* *}$ & & & & & $27.84^{* *}$ \\
\hline df & 2 & 2 & 2 & 2 & 2 & & & & & 8 \\
\hline $\begin{array}{c}\text { Dependent } \\
\text { variable }\end{array}$ & \multicolumn{10}{|c|}{ Explanatory variables (lag length $=4$ ) } \\
\hline $\mathrm{EE}$ & $79.54^{* *}$ & 3.41 & 3.91 & & & & & & & 7.14 \\
\hline LV & $11.06^{* *}$ & $64.82^{* *}$ & 3.18 & & & & & & & $13.74^{*}$ \\
\hline $\mathrm{LT}$ & 3.38 & 0.76 & $100.21^{* *}$ & & & & & & & 4.34 \\
\hline df & 4 & 4 & 4 & & & & & & & 8 \\
\hline Dependent & \multicolumn{10}{|c|}{ Explanatory variables (lag length $=4$ ) } \\
\hline variable & BG & $\mathrm{RO}$ & & & & & & & & Joint \\
\hline$\overline{B G}$ & $22.41^{* *}$ & $25.81^{* *}$ & & & & & & & & $25.81^{* *}$ \\
\hline $\mathrm{RO}$ & $21.18^{* *}$ & $200.21^{* *}$ & & & & & & & & $21.18^{* *}$ \\
\hline $\mathrm{df}$ & 4 & 4 & & & & & & & & 4 \\
\hline
\end{tabular}

a The number in each cell is the Wald test statistic, which, under the null, is asymptotically distributed as $\chi^{2}$.

${ }^{\mathrm{b}}$ df stands for the degrees of freedom. ${ }^{* *}\left(^{*}\right)$ denotes rejection of the null hypothesis $\Gamma_{k}=0$ at the $5 \%(10 \%)$ level of significance. CY is for Cyprus, CZ for the Czech Republic, EE for Estonia, HU for Hungary, LV for Latvia, LT for Lithuania, PL for Poland, SK for the Slovak Republic, SV for Slovenia, BG for Bulgaria and RO for Romania. 
Table 5

Testing for long run interdependence: Trace and $\lambda_{\max }$ statistics

\begin{tabular}{|c|c|c|c|c|c|c|}
\hline \multirow[b]{2}{*}{$(p-r)$} & \multicolumn{2}{|c|}{$\begin{array}{c}\text { CY, CZ, EE, HU, } \\
\text { LV, LT, SK, SV }\end{array}$} & \multicolumn{2}{|c|}{ CZ, HU, SK, SV } & \multicolumn{2}{|c|}{$\begin{array}{l}5 \% \text { critical values } \\
\text { for Model } 1^{*}\end{array}$} \\
\hline & Trace & $\lambda_{\max }$ & Trace & $\lambda_{\max }$ & Trace & $\lambda_{\max }$ \\
\hline 8 & 241.47 & $64.00^{*}$ & & & 169.60 & 53.19 \\
\hline 7 & $177.47^{\prime}$ & $51.24^{*}$ & & & 134.68 & 47.08 \\
\hline 6 & 126.23 & $43.43^{*}$ & & & 103.85 & 40.96 \\
\hline 5 & $82.80^{*}$ & 31.11 & & & 76.97 & 34.81 \\
\hline 4 & 51.69 & 21.96 & $57.42^{*}$ & $36.25^{*}$ & 54.08 & 28.59 \\
\hline 3 & 29.73 & 13.38 & 21.17 & 11.26 & 35.19 & 22.30 \\
\hline 2 & 16.35 & 9.79 & 9.91 & 7.38 & 20.26 & 15.89 \\
\hline 1 & 6.56 & 6.56 & 2.53 & 2.53 & 9.16 & 9.16 \\
\hline$k^{\mathrm{a}}$ & \multicolumn{2}{|c|}{3} & & & \\
\hline Model & \multicolumn{2}{|c|}{$1^{*}$} & $1^{*}$ & & & \\
\hline & \multicolumn{2}{|c|}{ EE, LV, LT } & \multicolumn{2}{|c|}{$\mathrm{BG}, \mathrm{RO}$} & \multicolumn{2}{|c|}{$\begin{array}{l}5 \% \text { critical values } \\
\text { for Model } 0\end{array}$} \\
\hline$(p-r)$ & Trace & $\lambda_{\max }$ & Trace & $\lambda_{\max }$ & Trace & $\lambda_{\max }$ \\
\hline 3 & $34.42^{*}$ & $23.71^{*}$ & & & 24.28 & 17.80 \\
\hline 2 & 10.71 & 9.06 & $41.66^{*}$ & $38.96^{*}$ & 12.32 & 11.22 \\
\hline 1 & 1.70 & 1.70 & 2.70 & 2.70 & 4.13 & 4.13 \\
\hline$k$ & \multicolumn{2}{|c|}{1} & \multirow{2}{*}{\multicolumn{2}{|c|}{ 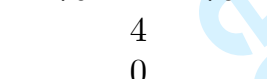 }} & & \\
\hline Model & \multicolumn{2}{|c|}{0} & & & & \\
\hline
\end{tabular}

The value reported at the top of each column is for $r=0$, so that $p-r=p$, where $p$ is the number of common trends included. ${ }^{*}$ denotes rejection of the null hypothesis at most $r$ cointegrating relations at the $5 \%$ level of significance. ${ }^{a} k$ indicates the lag length. CY is for Cyprus, CZ for the Czech Republic, EE for Estonia, HU for Hungary, LV for Latvia, LT for Lithuania, SK for the Slovak Republic, SV for Slovenia, BG for Bulgaria and RO for Romania. 